\title{
Statistical Evaluation of Anthropometric Measures and Oral Health Status in Terms of Diet, Smoking and Brushing Habits
}

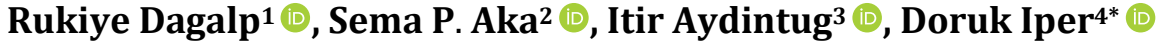 \\ ${ }^{1}$ Department of Statistics, Faculty of Science, University of Ankara, Ankara, Turkey \\ ${ }^{2}$ Department of Prosthodontics and Unit of Forensic Odontology, Faculty of Dentistry, University of Ankara (Retired). \\ Independent Researcher and Head of the Commission of Forensic Odontology, Turkish Forensic Scientists Society, Ankara, \\ Turkey \\ ${ }^{3}$ Associate Programme of Dental Prosthetics Technology, Technical College, University of Kapadokya, Urgup, Turkey \\ ${ }^{4}$ Department of English Language and Literature, Faculty of Arts and Sciences, Cankaya University, Ankara, Turkey \\ Email: rukiyedagalp@gmail.com, akasema@gmail.com, itiraydintug@hotmail.com, ^akadental@gmail.com
}

How to cite this paper: Dagalp, R., Aka, S.P., Aydintug, I. and Iper, D. (2019) Statistical Evaluation of Anthropometric Measures and Oral Health Status in Terms of Diet, Smoking and Brushing Habits. Health, 11, 391-405.

https://doi.org/10.4236/health.2019.114035

Received: March 25, 2019

Accepted: April 25, 2019

Published: April 28, 2019

Copyright $\odot 2019$ by author(s) and Scientific Research Publishing Inc. This work is licensed under the Creative Commons Attribution International License (CC BY 4.0).

http://creativecommons.org/licenses/by/4.0/

\begin{abstract}
Introduction and Objective: The aim of this research was to find out the interaction of anthropometric measurements particularly body mass and oral health status of Turkish young adult nationals regionally, depending on the effects of diet (food and fluid consumption), smoking and tooth brushing habits, which were determined by using the body mass index (BMI) and dental health index (DMFT). Material and Methods: The BMI and DMFT of 202 cases, with an age average 22.5 years, were recorded through physical and clinical examinations. Statistical evaluation of the data was checked by Cronbach's Alpha Reliability Scale and performed by analysis of variance, Somer's d and Pearson Chi-Square statistics, Poisson Regression and Odds Ratio analysis. Results: The results showed that the mean of BMI was at the optimum level (21.52) for all cases. The DMFT was higher for underweight females and for overweight males. The mean of DMFT according to sexes seemingly had no significant difference; however, females had $8.6 \%$ more DMFT than males. When the risk factors of dental caries were evaluated, the DMFT was found as $19.3 \%$ more for cases consuming high carbohydrate foods, $4.5 \%$ more for high beverage consumption and $18 \%$ more for smokers. Conclusions: In conclusion, tooth brushing 3 or more times a day is necessary to decrease the DMFT and tooth brushing 3 times a day as opposed to 1 or 2 times shows significant difference regarding oral health.
\end{abstract}

*Corresponding Author Doruk Iper: akadental@gmail.com. 


\section{Keywords}

Anthropometric Measures (BMI), Dental Index (DMFT), Oral Health, Diet, Smoking, Tooth Brushing

\section{Introduction}

\subsection{The Body Mass Status}

The sanity of human health is interdependent of a myriad of factors. It has been reported that deterioration of oral health is a risk factor which generally effects the overall health and quality of life [1] [2]. Diet habits also have an influence on the general health, especially on the body mass index (BMI) or Quetelet Index (QI), which can be calculated by the ratio of body weight in kilograms to square of the height in meters and serves as a measure for the state of general health and an acceptable tool for the estimation of deviations from optimum body mass index [3]. The relationship concerning anthropometric measures (height, weight, and BMI), the dental health of a person and diet habits, are well documented [4] [5] [6]. According to BMI classification, scores below 18.5 are regarded as underweight, between 18.5 - 25 as optimum, between 25 - 30 as overweight and above $30 \mathrm{~kg} / \mathrm{m}^{2}$ as obesity [7].

\subsection{Oral Health Status}

Diet, smoking and poor tooth brushing habits are influential risk factors regarding oral health. The state of oral health can be indicated by recording the number of decayed (D), missing (M) and filled (F) or restored teeth, known as the DMFT index for permanent teeth (T), which is a world-wide accepted and used system of diagnosis in the field of oral health, and also the most important indicator of dental health. DMFT index numerically shows the total number of Decayed, Missing and Filled permanent Teeth of a case. The main component is the dental decay which is a chronic irreversible disease of dental hard tissue that creates a need for restoration or at the stage beyond repair, an extraction of the tooth may be required. In case the third molar teeth are excluded, the score of DMFT ranges between $0-28$, otherwise $0-32$. This score must be written in lower case letters for primary teeth as "dmft" where the scores range from 0 - 20.

A research concerning the oral health diseases among 658 young adolescents, aged 10 - 14 years was conducted at Addis Ababa, Ethiopia, through interview and oral examinations, where prevalence of dental caries was found $47.4 \%$, which was associated with risk factors as: age, sweets intake, tooth cleaning, poor oral hygiene and being from a poor household [8]. In another research it was stated that the proportion of teeth that were decayed, missing, or filled, nearly doubled between ages 15 and 26 years [9]. Essentially the primary cause of dental caries-demineralization of the tooth hard tissue-is the activity of Streptococcus mutans' bacterial metabolism, which alters the homeostasis of the oral 
cavity by releasing acidic by-products and reducing the $\mathrm{pH}$ in the oral cavity below 5.5 (under normal conditions the $\mathrm{pH}$ of oral cavity is between $6.75-7.25$ ) by the fermentation of dietary carbohydrates and sugar-containing drinks that predisposes a media for dental caries [10] [11] [12]. Additionally it is stated that, the metabolic activity of Streptococcus mutans bacterium propagates with the intake of nicotine [13].

This research is principally based on the factors such as diet and cigarette habits that are accepted among the major factors affecting the colonization of this specific Streptococcus mutans bacteria and formation of dental caries; however the effects of microorganism activities remain beyond the scope of this research. In addition, the extent of the effect of the tooth brushing factor on the prevention of tooth decay has also been assessed. The aim of this research was to investigate the interaction among BMI and DMFT status of Turkish young adult nationals regionally, depending on the effects of diet (carbohydrate and beverage consumption), smoking and effectiveness of tooth brushing habits.

\section{Materials and Methods}

The data of this study were obtained from the volunteer participation of the faculty students in to the health screening and questionnaire, under the permission of Medical Director of Dentistry Hospital of Ankara University Faculty of Dentistry, dated November 07,2018 . The study was carried out in accordance with the principles of the Declaration of Helsinki.

In this research, body mass and oral health status of 202 cases (100 male, 102 female) with an average age of 22.5 years (range 20 - 25) were recorded through physical and clinical examinations carried out by the second author who is a qualified dental professional and had undergone standardization and measurement training. The sample size was calculated at least for 156 cases depending on a statistical power of $85 \%$ and $\alpha$-error of $5 \%$. The effective size for the lowest odds-ratio 1.045 was required for 174 cases as sample size, conversely effective size for the highest odds-ratio 1.398 was required for 156 cases as sample size. However, in this study the sample size was taken as 202 cases for a more reliable result. These cases were from the five regions of Turkey which were; $17.8 \%$ West, 8.5\% East, 19.3\% North, 16.3\% South and 38.1\% from the Center.

During the clinical survey, anamneses were taken from each individual; showing their food and drinking preferences, the amount of cigarettes they smoke if they are a smoker and the frequency of their tooth brushing. Afterwards, the height and weight of the individuals were measured in physical examination and recorded. During the physical examinations, the BMI index was calculated by dividing the body weight in kilograms to the square of the body height in meters for young adult subjects of both sexes. To numerically identify the oral health status for each individual, the total number of DMFT index were recorded according to regions of Turkey. Third molars 18, 28, 38 and 48 were excluded from this research due to the excessive variations of these teeth, therefore the survey was conducted on the 28 permanent teeth of each in- 
dividual. The limitations of this method appear for dentition where there are congenital absence or impact status of any tooth, where the examination of such tooth requires radiographs for accurate assessment of missing tooth.

In this research, the factors associated with dental health such as the groups of food (carbohydrate-rich foods versus protein and fiber-rich foods) and fluid consumption preferences (beverage, fruit juice other than water versus bottled natural mineral water which originates from natural or underground sources such as an underground reservoir or spring) [14], smoking habits (smoking versus non-smokers) and brushing habits (1 or 2 times a day versus 3 or more times a day) were recorded and the dataset was statistically evaluated. Statistical analysis methods used for this research were Pearson Chi-squared test, Student's $t$ test and odds-ratios used for comparison of proportions according to different groups.

\section{Results}

The reliability of this research was tested according to the Cronbach's Alpha Reliability Scale and intraclass correlation, which define the strong relation of variables with each other in the dataset. These scales gave a reliability coefficient of 78.7\%, that presents high internal consistency among the variables (minimum acceptable value is considered to be 70\%) [15]. Additionally, DMFT index was fitted by Poisson Regression on the variables; sex, region, food, drinking, smoking and brushing habits, where the model was found significant ( $\mathrm{p}$ value $=0.009$ $<0.05)$.

\subsection{The Body Mass Status}

The result of physical examinations of this research performed on 202 subjects, with an age range of $20-25$, showed that the BMI was; minimum 16.33, maximum 29.71 where the mean was 21.52 which falls in to the optimum level (Table 1). The frequency of sex and BMI in total cases showed that, $79.7 \%$ of cases were within the confines of normal BMI range, and the frequency of BMI due to sexes showed that, females were more in the underweight group whereas males were more in the overweight group (Table 2). According to analysis of variance, Somer's d and Pearson Chi-Square statistics, BMI was statistically significant for sexes ( $\mathrm{p}$ value $<0.05$ ), where the difference stems especially from the underweight group. When the distribution of DMFT was examined, for the relation among BMI and sexes due to regions by cross tabulation, it is found that there was a statistical significance for underweight and overweight groups ( $\mathrm{p}$ value $<$ 0.05). The maximum DMFT percentage for underweight female cases were at West (30.1\%) and for overweight male cases were at East (18.4\%), however the maximum optimal normal weight cases took place at the Center for both sexes (female cases $23.0 \%$, male cases $18.3 \%$ ) (Table 3 ).

\subsection{Oral Health Status}

In this research, during the clinical examination it was found that, out of 5656 
teeth, 1201 teeth were in the scope of DMFT; where 579 were decayed, 80 were missing and 542 were filled. There was no significant difference between average DMFT according to sexes ( $\mathrm{p}$ value $>0.05$ ). As a control group intact tooth was taken to determine the Odds Ratios (OR), which is a measure of association between the variable of interest (taken as an exposure) and an outcome [16]. According to OR, the tooth DMFT was $8.6 \%$ more for females than males (Table 4). The designated factors that affect oral health status which are; diet (food and fluid consumption), smoking and tooth brushing were examined and the statistical results are given below.

\subsubsection{Diet Habits (Food and Fluid Consumption)}

This research revealed that the DMFT of cases were $19.3 \%$ more for individuals consuming high carbohydrated food diet, compared to diets with protein and fibrous food. According to daily beverage consumption; DMFT was found as $4.5 \%$ more for individuals who prefer to consume juice, for their need for water, rather than drinking mineral water (Table 5). The frequency of DMFT according to the regions and diet habits showed that the diet of the subjects was generally based on the Carbohydrate rich foods and the DMFT for people who consume protein and fiber rich foods, showed a decrease up to 19.8, 5.9, 5.4, 29.3 and 9.5 times respectively for West, East, North, South and Central regions of Turkey, when compared to cases consuming carbohydrate rich foods (Table 6). The caries' prevalence DMFT due to the regions and drinking habits also indicate decrease up to 7.0, 3.3, 8.1, 2.2 and 8.9 times respectively for West, East, North, South and Central regions of Turkey, for people consuming mineral water, compared to high consumption of beverages (Table 7).

\subsubsection{Smoking Habits}

In this study smoking habit was determined as another factor increasing DMFT which was found as $18 \%$ more for smokers than non-smokers as seen in Table 5. Among the subjects 70 individuals were smokers, $25.7 \%$ of which were females, who were smoking average 9 cigarettes daily and $74.3 \%$ of them were males who smoke average 10.9 cigarettes daily (minimum 1 to maximum 30 cigarettes daily, mean 10.41 std. 6712). The maximum percentage of smokers of both sexes were seen at the Centeral region (41.4\%).

\subsubsection{Tooth Brushing Habits}

The DMFT was found $18.5 \%$ more when tooth brushing was done 1 or 2 times as opposed to 3 or more times, in addition to brushing 1 or 2 times per day, DMFT was increased by $39.8 \%$ when the diet mainly includes carbohydrates and in the case where the diet includes beverages DMFT was increased by $24.7 \%$ seen in Table 5. The decrease rate of DMFT for the cases who brush their teeth 3 or more times instead of 1 or 2 times a day were as follows; for non-smokers it was $7.5 \%$, for people who smoke 1 - 10 cigarettes a day it was $4.7 \%$, for the last group who smoke more than 11 cigarettes a day it was $23.4 \%$ (Table 8 ). The frequency of DMFT according to the regions and brushing habits present decrease up to 
4.1, 6.5, 82.3, 14.4 and 4.8 times respectively for West, East, North, South and Central regions of Turkey, for people who brush their teeth 3 or more times a day, compared to 1 or 2 times a day (Table 9). After eliminating the effects of high carbohydrate foods, beverages and cigarette consumption, the results showed that daily 3 or more times brushing decreases the DMFT by $31.0 \%$ (Table 10).

Table 1. Descriptive statistics of young adults' body mass index (BMI) for 202 cases (102 female, 100 male).

\begin{tabular}{ccccc}
\hline Variables & Minimum & Maximum & Mean & Std. Deviation \\
\hline Age (Year) & 20 & 25 & 22.51 & 1.22 \\
Stature $(\mathrm{cm})$ & 151 & 190 & 170.40 & 8.54 \\
Body Weight $(\mathrm{Kg})$ & 44 & 96 & 62.90 & 11.55 \\
BMI $\left(\mathrm{Kg} / \mathrm{cm}^{2}\right)$ & 16.33 & 29.71 & 21.52 & 2.67 \\
Female BMI $\left(\mathrm{Kg} / \mathrm{cm}^{2}\right)$ & 16.33 & 29.71 & 20.27 & 2.25 \\
Male BMI $\left(\mathrm{Kg} / \mathrm{cm}^{2}\right)$ & 16.72 & 29.35 & 22.80 & 2.45 \\
\hline
\end{tabular}

Table 2. Frequency of sex and BMI among total cases.

\begin{tabular}{ccccc}
\hline \multirow{2}{*}{ Sex } & \multicolumn{3}{c}{ BMI } & Sex \% in Total \\
\cline { 2 - 4 } & Under weight \% & Normal weight \% & Over weigh t\% & 50.5 \\
Female & 17.6 & 78.4 & 3.9 & 49.5 \\
Male & 3 & 81 & 16 & 100 \\
$\begin{array}{c}\text { BMI \% in Total } \\
\left(\mathrm{Kg} / \mathrm{cm}^{2}\right)\end{array}$ & 10.4 & 79.7 & 9.9 & \\
\hline
\end{tabular}

Table 3. Frequency ofBMI and DMFT indexes according to the sex and regions.

\begin{tabular}{|c|c|c|c|c|c|c|c|c|c|c|}
\hline \multirow[b]{2}{*}{ Region } & \multirow[b]{2}{*}{ Sex } & \multicolumn{3}{|c|}{ Under weight } & \multicolumn{3}{|c|}{ Normal weight } & \multicolumn{3}{|c|}{ Over weight } \\
\hline & & $\begin{array}{c}\% \\
\text { of } \mathrm{N}\end{array}$ & $\begin{array}{c}\text { Mean of } \\
\text { DMFT }\end{array}$ & $\begin{array}{c}\% \text { of } \\
\text { DMFT }\end{array}$ & $\begin{array}{c}\% \\
\text { of } \mathrm{N}\end{array}$ & $\begin{array}{c}\text { Mean of } \\
\text { DMFT }\end{array}$ & $\begin{array}{c}\% \text { of } \\
\text { DMFT }\end{array}$ & $\begin{array}{c}\% \\
\text { of } \mathrm{N}\end{array}$ & $\begin{array}{c}\text { Mean of } \\
\text { DMFT }\end{array}$ & $\begin{array}{c}\% \text { of } \\
\text { DMFT }\end{array}$ \\
\hline \multirow{3}{*}{ West } & Female & 23.8 & 7.6 & 30.1 & 7.5 & 5.3 & 7.2 & 0.0 & $0^{*}$ & 0.0 \\
\hline & Male & 4.8 & 7.0 & 4.9 & 9.9 & 5.5 & 8.8 & 10.0 & 3.5 & 7.0 \\
\hline & Total & 28.6 & 7.5 & 35.0 & 17.4 & 5.4 & 16.0 & 10.0 & 3.5 & 7.0 \\
\hline \multirow{3}{*}{ East } & Female & 0.0 & 0 & 0.0 & 1.9 & 7.0 & 2.0 & 0.0 & 0 & 0.0 \\
\hline & Male & 0.0 & 0 & 0.0 & 7.5 & 3.8 & 5.3 & 10.0 & 9.5 & 18.4 \\
\hline & Total & 0.0 & 0 & 0.0 & 9.3 & 4.5 & 7.3 & 10.0 & 9.5 & 18.4 \\
\hline \multirow{3}{*}{ North } & Female & 14.3 & 6.7 & 15.4 & 11.2 & 5.5 & 11.0 & 10.0 & 8.0 & 14.0 \\
\hline & Male & 4.8 & 10 & 7.0 & 7.5 & 6.5 & 8.7 & 15.0 & 6.7 & 17.5 \\
\hline & Total & 19.0 & 7.5 & 22.4 & 18.6 & 5.9 & 19.7 & 25.0 & 7.2 & 31.6 \\
\hline \multirow{3}{*}{ South } & Female & 14.3 & 5.7 & 11.2 & 7.5 & 5.8 & 7.5 & 0.0 & 0 & 0.0 \\
\hline & Male & 0.0 & 0 & 0.0 & 8.7 & 5.4 & 8.2 & 20.0 & 3.3 & 17.5 \\
\hline & Total & 14.3 & 5.7 & 11.2 & 16.1 & 5.5 & 15.7 & 20.0 & 3.3 & 17.5 \\
\hline
\end{tabular}




\section{Continued}

\begin{tabular}{ccccccccccc}
\hline & Female & 33.3 & 5.4 & 28.0 & 21.7 & 6.0 & 23.0 & 10.0 & 4.5 & 8.8 \\
Center & Male & 4.8 & 5.0 & 3.5 & 16.8 & 6.3 & 18.3 & 25.0 & 3.6 & 16.7 \\
& Total & 38.1 & 5.4 & 31.5 & 38.5 & 6.2 & 41.3 & 35.0 & 3.9 & 25.4 \\
& Female & 85.7 & 6.3 & 84.6 & 49.7 & 5.8 & 50.7 & 20.0 & 6.3 & 22.8 \\
\multirow{2}{*}{ Total } & Male & 14.3 & 7.3 & 15.4 & 50.3 & 5.7 & 49.3 & 80.0 & 4.8 & 77.2 \\
& Total & 100.0 & 6.4 & 100.0 & 100.0 & 5.7 & 100.0 & 100.0 & 5.1 & 100.0 \\
\hline
\end{tabular}

${ }^{\star} 0$ means no cases present at this region.

Table 4. Frequency of DMFT versus intact tooth among total number of tooth examined for both sexes (Odds Ratio $=1.086$, DMFT was $8.6 \%$ more for females than males).

\begin{tabular}{cccc}
\hline Sex & DMFT & Intact Tooth & Total Tooth \\
\hline Female & 626 & 2230 & 2856 \\
Male & 575 & 2225 & 2800 \\
Total & 1201 & 4455 & 5656 \\
\hline
\end{tabular}

Table 5. Frequency of DMFT for food, drinking, smoking and brushing habits.

\begin{tabular}{|c|c|c|c|c|c|}
\hline Habits & Preference & $\begin{array}{c}\mathrm{N} \text { of } \\
\text { DMFT }\end{array}$ & $\begin{array}{c}\mathrm{N} \text { of Intact } \\
\text { Tooth }\end{array}$ & $\begin{array}{l}\mathrm{N} \text { of Total } \\
\text { Tooth }\end{array}$ & $\begin{array}{l}\text { Odds } \\
\text { Ratios }\end{array}$ \\
\hline \multirow{3}{*}{ Food Consumption } & Carbohydrate $R F^{*}$ & 1046 & 4106 & 5152 & \multirow{3}{*}{1.193} \\
\hline & Protein and Fiber RF & 112 & 392 & 504 & \\
\hline & Total & 1158 & 4498 & 5656 & \\
\hline \multirow{3}{*}{ Drinking Consumption } & Beverages & 1022 & 3766 & 4788 & \multirow{3}{*}{1.045} \\
\hline & Mineral Water & 179 & 689 & 868 & \\
\hline & Total & 1201 & 4455 & 5656 & \\
\hline Smoking Habit ${ }^{* *}$ & Smoker & 388 & 1572 & 1960 & \\
\hline $\begin{array}{l}\text { [For } 70 \text { smoker and } \\
\text { randomly chosen } 70\end{array}$ & Non-smoker & 339 & 1621 & 1960 & 1.180 \\
\hline \multirow[t]{2}{*}{ Non-smoker] } & Total & 727 & 3193 & 3920 & \\
\hline & 1 or 2 & 1053 & 3819 & 4872 & \multirow{3}{*}{1.185} \\
\hline \multirow[t]{2}{*}{ Brushing } & 3 or more & 148 & 636 & 784 & \\
\hline & Total & 1201 & 4455 & 5656 & \\
\hline Daily brushing habit & 1 or 2 & 969 & 3383 & 4352 & \multirow{3}{*}{1.398} \\
\hline $\begin{array}{c}\text { for cases consuming } \\
\text { preferably }\end{array}$ & 3 or more & 119 & 581 & 700 & \\
\hline Carbohydrate $R F$ & Total & 1088 & 3964 & 5052 & \\
\hline \multirow{3}{*}{$\begin{array}{l}\text { Daily brushing habit } \\
\text { for cases consuming } \\
\text { preferably beverages }\end{array}$} & 1 or 2 & 899 & 3217 & 4116 & \multirow{3}{*}{1.247} \\
\hline & 3 or more & 123 & 549 & 672 & \\
\hline & Total & 1022 & 3766 & 4788 & \\
\hline
\end{tabular}

${ }^{*}$ RF: Rich Food, ${ }^{*}$ Smoking Habit was not homogenous for the young adults (number of non-smokers were $65 \%$, smokers were $35 \%$ ), therefore randomly equal number of cases (70 for each) were selected. 
Table 6. Frequency of DMFT according to the regions and diet habits.

\begin{tabular}{|c|c|c|c|c|c|c|}
\hline Region & Diet Habit & $\begin{array}{l}\mathrm{N} \text { of } \\
\text { Tooth }\end{array}$ & $\begin{array}{l}\mathrm{N} \text { of } \\
\text { DMFT }\end{array}$ & $\begin{array}{l}\% \text { of DMFT } \\
\text { out of Total }\end{array}$ & $\begin{array}{c}\% \text { of DMFT } \\
\text { within Region }\end{array}$ & $\begin{array}{c}\text { Amount of } \\
\text { Decrease Rate }\end{array}$ \\
\hline \multirow{3}{*}{ West } & Carbohydrate $R F^{*}$ & 952 & 199 & 16.6 & 95.2 & \multirow{3}{*}{19.8} \\
\hline & Protein and fiber $R F$ & 56 & 10 & 0.8 & 4.8 & \\
\hline & Total & 1008 & 209 & 17.4 & 100 & \\
\hline \multirow{3}{*}{ East } & Carbohydrate $R F$ & 392 & 77 & 6.4 & 85.6 & \multirow{3}{*}{5.9} \\
\hline & Protein and fiber $R F$ & 84 & 13 & 1.1 & 14.4 & \\
\hline & Total & 476 & 90 & 7.5 & 100 & \\
\hline \multirow{3}{*}{ North } & Carbohydrate $R F$ & 952 & 214 & 17.8 & 84.3 & \multirow{3}{*}{5.4} \\
\hline & Protein and fiber $R F$ & 140 & 40 & 3.3 & 15.7 & \\
\hline & Total & 1092 & 254 & 21.1 & 100 & \\
\hline \multirow{3}{*}{ South } & Carbohydrate $R F$ & 868 & 178 & 14.8 & 96.7 & \multirow{3}{*}{29.3} \\
\hline & Protein and fiber $R F$ & 56 & 6 & 0.5 & 3.3 & \\
\hline & Total & 924 & 184 & 15.3 & 100 & \\
\hline \multirow{3}{*}{ Center } & Carbohydrate $R F$ & 1988 & 420 & 35.0 & 90.5 & \multirow{3}{*}{9.5} \\
\hline & Protein and fiber $R F$ & 168 & 44 & 3.7 & 9.5 & \\
\hline & Total & 2156 & 464 & 38.6 & 100 & \\
\hline \multirow{3}{*}{ Total } & Carbohydrate $R F$ & 5152 & 1088 & 90.6 & 90.6 & \multirow{3}{*}{9.6} \\
\hline & Protein and fiber $R F$ & 504 & 113 & 9.4 & 9.4 & \\
\hline & Total & 5656 & 1201 & 100.0 & 100.0 & \\
\hline
\end{tabular}

${ }^{\star}$ RF: Rich Food.

Table 7. Frequency of DMFT according to regions and drinking habits.

\begin{tabular}{|c|c|c|c|c|c|c|}
\hline Region & Drink Variety & $\begin{array}{l}\mathrm{N} \text { of } \\
\text { Cases }\end{array}$ & $\begin{array}{l}\mathrm{N} \text { of } \\
\text { DMFT }\end{array}$ & $\begin{array}{l}\% \text { of DMF out } \\
\text { of Total DMFT }\end{array}$ & $\begin{array}{c}\% \text { of DMFT } \\
\text { within Region }\end{array}$ & $\begin{array}{c}\text { Amount of } \\
\text { Decrease Rate }\end{array}$ \\
\hline \multirow{3}{*}{ West } & Beverages & 896 & 183 & 15.2 & 87.6 & \multirow{3}{*}{7.0} \\
\hline & Mineral water & 112 & 26 & 2.2 & 12.4 & \\
\hline & Total & 1008 & 209 & 17.4 & 100 & \\
\hline \multirow{3}{*}{ East } & Beverages & 364 & 69 & 5.7 & 76.7 & \multirow{3}{*}{3.3} \\
\hline & Mineral water & 112 & 21 & 1.7 & 23.3 & \\
\hline & Total & 476 & 90 & 7.5 & 100 & \\
\hline \multirow{3}{*}{ North } & Beverages & 952 & 226 & 18.8 & 89 & \multirow{3}{*}{8.1} \\
\hline & Mineral water & 140 & 28 & 2.3 & 11 & \\
\hline & Total & 1092 & 254 & 21.1 & 100 & \\
\hline \multirow{3}{*}{ South } & Beverages & 644 & 127 & 10.6 & 69 & \multirow{3}{*}{2.2} \\
\hline & Mineral water & 280 & 57 & 4.7 & 31 & \\
\hline & Total & 924 & 184 & 15.3 & 100 & \\
\hline \multirow{3}{*}{ Center } & Beverages & 1932 & 417 & 34.7 & 89.9 & \multirow{3}{*}{8.9} \\
\hline & Mineral water & 224 & 47 & 3.9 & 10.1 & \\
\hline & Total & 2156 & 464 & 38.6 & 100 & \\
\hline \multirow{3}{*}{ Total } & Beverages & 4788 & 1022 & 85.1 & 85.1 & \multirow{3}{*}{5.7} \\
\hline & Mineral water & 868 & 179 & 14.9 & 14.9 & \\
\hline & Total & 5656 & 1201 & 100.0 & 100 & \\
\hline
\end{tabular}


Table 8. Frequency of DMFT for smoking and brushing habits.

\begin{tabular}{|c|c|c|c|c|c|c|}
\hline Smoking Habit & Daily Brushing Habit & $\begin{array}{l}\mathrm{N} \text { of } \\
\text { Tooth }\end{array}$ & $\begin{array}{l}\mathrm{N} \text { of } \\
\text { DMFT }\end{array}$ & $\begin{array}{c}\% \text { of } \\
\text { DMFT out } \\
\text { of Total }\end{array}$ & $\begin{array}{c}\% \text { of DMFT } \\
\text { within } \\
\text { Region }\end{array}$ & $\begin{array}{c}\text { Amount of } \\
\text { Decrease } \\
\text { Rate }\end{array}$ \\
\hline \multirow{3}{*}{ Non-smoker } & 1 or 2 & 3136 & 717 & 59.7 & 88.2 & \multirow{3}{*}{7.5} \\
\hline & 3 or more & 560 & 96 & 8.0 & 11.8 & \\
\hline & Total & 3696 & 813 & 67.7 & 100 & \\
\hline \multirow{3}{*}{$\begin{array}{c}1-10 \\
\text { cigarettes/day }\end{array}$} & 1 or 2 & 1036 & 219 & 18.2 & 82.3 & \multirow{3}{*}{4.7} \\
\hline & 3 or more & 196 & 47 & 3.9 & 17.7 & \\
\hline & Total & 1232 & 266 & 22.1 & 100 & \\
\hline \multirow{3}{*}{$\begin{array}{l}\text { More than } 11 \\
\text { cigarettes/day }\end{array}$} & 1 or 2 & 700 & 117 & 9.7 & 95.9 & \multirow{3}{*}{23.4} \\
\hline & 3 or more & 28 & 5 & 0.4 & 4.1 & \\
\hline & Total & 728 & 122 & 10.2 & 100 & \\
\hline \multirow{3}{*}{ Total } & 1 or 2 & 4872 & 1053 & 87.7 & 87.7 & \multirow{3}{*}{7.1} \\
\hline & 3 or more & 784 & 148 & 12.3 & 12.3 & \\
\hline & Total & 5656 & 1201 & 100.0 & 100 & \\
\hline
\end{tabular}

Table 9. Descriptive analysis of DMF according to regions and brushing habits.

\begin{tabular}{|c|c|c|c|c|c|c|}
\hline Region & $\begin{array}{c}\text { Brushing } \\
\text { Habit/Times } \\
\text { a Day }\end{array}$ & $\begin{array}{l}\mathrm{N} \text { of } \\
\text { Cases }\end{array}$ & $\mathrm{N}$ of $\mathrm{DMF}$ & $\begin{array}{c}\text { of DMF out of } \\
\text { Total DMF }\end{array}$ & $\begin{array}{l}\text { of DMF } \\
\text { within } \\
\text { Region }\end{array}$ & $\begin{array}{c}\text { Amount of } \\
\text { Decrease Rate }\end{array}$ \\
\hline \multirow{3}{*}{ West } & 1 or 2 & 840 & 168 & 14.0 & 80.4 & \multirow{3}{*}{4.1} \\
\hline & 3 or more & 168 & 41 & 3.4 & 19.6 & \\
\hline & Total & 1008 & 209 & 17.4 & 100 & \\
\hline \multirow{3}{*}{ East } & 1 or 2 & 392 & 78 & 6.5 & 86.7 & \multirow{3}{*}{6.5} \\
\hline & 3 or more & 84 & 12 & 1.0 & 13.3 & \\
\hline & Total & 476 & 90 & 7.5 & 100 & \\
\hline \multirow{3}{*}{ North } & 1 or 2 & 1036 & 251 & 20.9 & 98.8 & \multirow{3}{*}{82.3} \\
\hline & 3 or more & 56 & 3 & 0.2 & 1.2 & \\
\hline & Total & 1092 & 254 & 21.1 & 100 & \\
\hline \multirow{3}{*}{ South } & 1 or 2 & 812 & 172 & 14.3 & 93.5 & \multirow{3}{*}{14.4} \\
\hline & 3 or more & 112 & 12 & 1.0 & 6.5 & \\
\hline & Total & 924 & 184 & 15.3 & 100 & \\
\hline \multirow{3}{*}{ Center } & 1 or 2 & 1792 & 384 & 32.0 & 82.8 & \multirow{3}{*}{4.8} \\
\hline & 3 or more & 364 & 80 & 6.7 & 17.2 & \\
\hline & Total & 2156 & 464 & 38.6 & 100 & \\
\hline \multirow{3}{*}{ Total } & 1 or 2 & 4872 & 1053 & 87.7 & 87.7 & \multirow{3}{*}{7.1} \\
\hline & 3 or more & 784 & 148 & 12.3 & 12.3 & \\
\hline & Total & 5656 & 1201 & 100.0 & 100.0 & \\
\hline
\end{tabular}


Table 10. The effect of tooth brushing on DMFT versus intact tooth among total number of tooth for the cases who consume high carbohydrate food, beverages and smoke.

\begin{tabular}{cccc}
\hline $\begin{array}{c}\text { Brushing Habit } \\
\text { /Times a Day }\end{array}$ & DMFT & Intact Tooth & Total Tooth \\
\hline 1 or 2 & 247 & 985 & 1232 \\
3 or more & 18 & 94 & 112 \\
Total & 265 & 1079 & 1344 \\
\hline
\end{tabular}

(Odds Ratio $=1.310$, DMFT was $31.0 \%$ more for cases who brush their teeth 1 or 2 times than 3 or more).

\section{Discussion}

In this research the association between anthropometric measures (BMI) and dental caries has been evaluated for 202 cases, with a mean age of 22.51 and significant results were obtained for the relation of BMI, sex and region due to DMFT ( $\mathrm{p}$ value $<0.05$ ). The frequency of sex and BMI in total cases showed that, $17.6 \%$ of females were in the underweight group where and $16 \%$ of the males were in the over weight group (Table 1 and Table 2). The results of this research showed that within the BMI groups, maximum DMFT percentage was observed for underweight female cases at West, overweight male cases at East and optimal cases at the Center for both sexes (Table 3). Plus, the mean of DMFT was $8.6 \%$ more for females than males according to OR as seen in (Table 4). Even though these results depend on the inhomogeneous distribution of the cases within the regions, the maximum consumption rates of all the factors were at the Center. This outcome not only shows the association of BMI, DMFT, carbohydrates, beverages and cigarettes, but also the interactions of these factors according to selected regions. This outcome not only shows the association of BMI, DMFT, carbohydrates, beverages and cigarettes, but also the interactions of these factors according to selected regions. These findings support a similar study that found that, tooth decay was associated with high and low body mass indexes [4]. Additionally a research conducted in India revealed that there was a significant association between the indexes of anthropometric measures and dental caries for the 15 - 19 year age group (caries scores of overweight males and females were higher), whereas there were no relation found for the age group of $12-14$ years [5]. These findings seem natural, as teeth at this age have recently erupted. A longitudinal investigation realized at Dunedin, New Zealand following cases in the age range of $5-26$ years proved that the number of decayed, missing, or filled teeth would be twofold between the ages 15 and 26 years [9].

A research conducted in Abu Dhabi on children with an age range from 18 months to 4 years showed that the frequent use of carbohydrated foods and high-sugar beverages was directly proportional with the DMFT which disclosed $41 \%$ dental caries for this age group [17]. Fluid intake data also had been analyzed for 2 - 10-year-old 5985 children and there was remarkably more dental caries detected in children who consume high carbonated drinks as opposed to 
children who consume; milk, water or juices, therefore accepted as a risk factor for dental caries for primary teeth [18]. A four-year study showed positive relation between consuming sugar sweetened beverages and dental caries among adults where DMFT was 33\% more for cases who drink beverages more than 3 times a day as compared to the control group [19]. A review of the literature, to find out the relationship between sucrose and dental caries, from years 1856 to 2007 revealed that, it is not the sugar amount, but its frequency which has a moderate significant relation with dental caries [20]. This research showed that, consuming carbohydrate rich foods rather than protein and fibrous food increases the risk for dental caries occurrence 19.3\%, preferring beverages and fruit juices instead of water increases caries formation rate as $4.5 \%$ (Table 5). On the contrary the \% of DMFT shows a decrease rate of totally 9.6 for people consuming protein and fiber rich foods and 5.7 for cases preferring mineral water (Table 6 and Table 7).

It is also found that not only food and drink intake, but also smoking may affect the oral health and sufficient daily tooth brushing is a major factor in decreasing the DMFT. In this study the ratio of smoking habits for females was one third of males which may be sourced culturally. However, the average number of cigarettes were approximate for both sexes. The results showed that; smoking habits were a factor, increasing the dental decay which caused $18 \%$ more tooth decay for smokers than non-smokers as seen in Table 5. The destructive effects of cigarette have not been fully observed for people who smoke a few cigarettes, since the average age of the individuals was 22.5 , however it provides a prediction that smoking may have an effect at the older ages. It is also shown that adequate daily tooth brushing especially 3 or more, significantly decrease the value of DMFT index. The highest prevalence of dental loss was seen for smokers who smoke more than 11 cigarettes/day $95.9 \%$ for cases who brush their teeth 1 or 2 times a day, conversely the decrease rate was 23.4 times when the subjects brush their teeth 3 or more times a day (Table 8). This result shows that the caries prevention effect of tooth brushing is much more evident for heavy smokers. These findings supported another research, where the effect of daily cigarette smoking factor on the increase of dental decay was examined on 955 adults by a 4-year clinical study, which proved that smokers had 1.7 times more decayed teeth than non-smokers where the rate for heavy smokers was twice as much. It is stated that tooth brushing frequency, sugar intake frequency and dental attendance explains only $20 \%$ of the effect of daily smoking on caries development [21].

It has been reported that, prevention of dental diseases is possible by; high quality foods coupled with healthy dietary modifications and personal hygiene measures such as, effective and daily regular brushing. It has to be noted however that ineffective tooth brushing has been shown as a factor associated with dental caries, although the frequency of brushing is adequate [22] [23] [24]. Another research conducted on oral hygiene practices of 12 - 13 years old school children supported our findings, DMFT was higher for cases who brush their 
teeth irregularly than cases who brush their teeth once or twice a day [25]. In a cross-sectional study performed on a sample of 658 children, aged 10 - 14 years, the frequency of tooth cleaning was shown as; $19.3 \%$ once a week, 38.5 few times a week, 32.6 once a day, other 9.6 where the prevalence of dental caries was $47.4 \%$. This study emphasized on public oral health education program [8].

It is clearly proved that, for all cases when tooth brushing was done 1 or 2 times as opposed to 3 or more times, DMFT was found $18.5 \%$ more, additionally for cases who mostly consume carbohydrate rich foods DMFT was $39.8 \%$ more, and for cases who consume beverages than mineral water the DMFT was $24.7 \%$ more (Table 5). The results also showed that; the decrease rates of DMFT were respectively; 7.5, 4.7, and 23.4 for non-smokers, for smokers who smoke $1-10$ cigarettes/day, and for smokers who smoke more than 11 cigarettes/day, for individuals who brush their tooth 3 or more times in a day versus 1 or 2 times (Table 8). Plus, the frequency of DMFT according to the regions and brushing habits present decrease up to $4.1,6.5,82.3,14.4$ and 4.8 times respectively for West, East, North, South and Central regions of Turkey (Table 9), and the results showed $31.0 \%$ decrease of DMFT, when the effects of high carbohydrate food, beverages and cigarette consumption were eliminated for cases, who daily brushed their teeth 3 or more times a day (Table 10). The statistical descriptive analysis of dental health status due to regions and brushing habits according to DMFT index shows that, tooth brushing must be done at least 3 times a day especially after each meal.

\section{Conclusions}

The following facts are derived from this research:

1) The average of body mass index (BMI) was $21.52 \%$ and $79.7 \%$ of the cases were within the confines of normal BMI range $(18.5$ - 25) for the adults, with an age average of 22.5 years.

2) Tooth decay was associated with high and low body mass indices. DMFT was slightly lower for individuals having optimal body index.

3) The mean of DMFT according to sexes showed 8.6\% more DMFT for females than males.

4) DMFT was found as $19.3 \%$ more for high carbohydrate food consuming diets and, $4.5 \%$ more for high beverage consuming diets.

5) The DMFT was found $18.5 \%$ more when tooth brushing was done 1 or 2 times as opposed to 3 or more times. In addition to brushing 1 or 2 times per day, DMFT was increased by $39.8 \%$ when the diet mainly consumes carbohydrates. As for the case of the diet that includes drinking beverages, when tooth brushing frequency was 1 or 2 times per day, the DMFT was $24.7 \%$.

6) Smokers showed $18 \%$ more DMFT than non-smokers. The highest prevalence of dental loss was detected for smokers who smoke more than 11 cigarettes/day but, it was found that smokers who brush their teeth 3 or more times a day showed a decrease rate of DMFT 23.4 times. It is evident that 3 or 
more times tooth brushing reduces the DMFT; therefore attention must be given to oral health measures such as tooth brushing after each meal.

7) The results showed that daily, 3 or more times tooth brushing decreases the DMFT by $31.0 \%$ when the effects of high carbohydrate food, beverages and smoke consumption were eliminated.

As expressed by the Bard hundreds of years ago, toothache is an excruciatingly painful thing to suffer, enough to break the most stoic of philosophers. The importance of taking good care of dental health, for children and adults alike, cannot be overstated.

"I pray thee, peace. I will be flesh and blood;

For there was never yet philosopher

That could endure the toothache patiently,

However they have writ the style of gods

And made a push at chance and sufferance". (Shakespeare W) [26]

Further research is recommended for the following subjects:

1) In this research the mean DMFT was slightly lower for individuals having optimal body index. This relation between body mass and dental caries should also be investigated for older age groups.

2) Dental health problems were found more for smokers than nonsmokers. However, the effects of smoking in this age group were not significant, as they are young and have been smoking for a few years yet. Therefore, such research for older ages should be conducted longitudinally for each decade.

\section{Acknowledgements}

As the authors of this research, would like to give our special thanks for the voluntary participation of our contributors, for the information they provide during their anamnesis records and clinical oral examinations. We also gratefully thank Bahar Aka MSc., for her sincere support during the study.

\section{Statement of Disclosure}

The authors of this study published the article in a consensus. There is no conflict of interest among the authors.

\section{References}

[1] Sheiham, A. (2005) Oral Health, General Health and Quality of Life. Bulletin of the World Health Organization, 83, 644.

[2] Petersen, P.E., Bourgeois, D., Ogawa, H., Estupinan-Day, S. and Ndiaye, C. (2005) The Global Burden of Oral Diseases and Risks to Oral Health. Bulletin of the World Health Organization, 83, 661-669.

[3] Bogin, B. and Varela Silva, M.I. (2012) The Body Mass Index: The Good, the Bad, and the Horrid. Société Suisse d Anthropologie (SSA), 18, 5-11.

[4] Hooley, M., Skouteris, H., Boganin, C., Satur, J. and Kilpatrick, N. (2012) Body Mass Index and Dental Caries in Children and Adolescents: A Systematic Review of 
Literature Published 2004 to 2011. Systematic Reviews, 1, 1-26.

https://doi.org/10.1186/2046-4053-1-57

[5] Chakravarthy, P.K., Suresh, G., Chenna, D. and Chenna, V. (2013) Relationship between Anthropometric Measures and Dental Caries among Adolescent National Cadets Corps of Udupi District, South India. Journal of Natural Science, Biology and Medicine, 4, 167-170. https://doi.org/10.4103/0976-9668.107284

[6] Kesim, S., Cicek, B., Aral, C.A., Ozturk, A., Mazıcıoglu, M.M. and Kurtoglu, S. (2016) Oral Health, Obesity Status and Nutritional Habits in Turkish Children and Adolescents: An Epidemiological Study. Balkan Medical Journal, 33, 164-172. https://doi.org/10.5152/balkanmedj.2016.16699

[7] Mardolkar, M. (2017) Body Mass Index (BMI) Data Analysis and Classification. International Journal of Computer Science and Mobile Computing, 6, 8-16.

[8] Berhane, H.Y. and Worku, A. (2014) Oral Health of Young Adolescents in Addis Ababa-A Community-Based Study. OJPM, 4, 640-648.

https://doi.org/10.4236/ojpm.2014.48073

[9] Broadbent, J.M. and Thomson, W.M. (2005) For Debate: Problems with the DMF Index Pertinent to Dental Caries Data Analysis. Community Dentistry and Oral Epidemiology, 33, 400-409. https://doi.org/10.1111/j.1600-0528.2005.00259.x

[10] Islam, B., Khan, S.N. and Khan, A.U. (2007) Dental Caries: From Infection to Prevention. Medical Science Monitor, 13, 196-203.

https://doi.org/10.1038/bdj.2007.728

[11] Marsh, P.D. (2009) Role of the Oral Microflora in Health. Microbial Ecology in Health and Disease, 12, 130-137. https://doi.org/10.1080/089106000750051800

[12] Mishra, M.B. and Mishra, S. (2011) Sugar-Sweetened Beverages: General and Oral Health Hazards in Children and Adolescents. International Journal of Clinical Pediatric Dentistry, 4, 119-123. https://doi.org/10.5005/jp-journals-10005-1094

[13] Huang, R., Li, M. and Gregory, R.L. (2012) Effect of Nicotine on Growth and Metabolism of Streptococcus mutans. European Journal of Oral Sciences, 120, 319-325. https://doi.org/10.1111/j.1600-0722.2012.00971.x

[14] Quattrini, S., Pampaloni, B. and Brandi, M.L. (2016) Natural Mineral Waters: Chemical Characteristics and Health Effects. Clinical Cases in Mineral and Bone Metabolism, 13, 173-180. https://doi.org/10.11138/ccmbm/2016.13.3.173

[15] Bruin, J. (2006) Newtest: Command to Compute New Test. UCLA: Statistical Consulting Group. https://stats.idre.ucla.edu/stata/ado/analysis

[16] Szumilas, M. (2010) Explaining Odds Ratios. Journal of the Canadian Academy of Child and Adolescent Psychiatry, 19, 227-229.

[17] Elamin, A., Garemo, M. and Gardner, A. (2018) Dental Caries and Their Association with Socioeconomic Characteristics, Oral Hygiene Practices and Eating Habits among Preschool Children in Abu Dhabi, United Arab Emirates-The NOPLAS Project. BMC Oral Health, 18, 104. https://doi.org/10.1186/s12903-018-0557-8

[18] Sohn, W., Burt, B.A. and Sowers, M.R. (2006) Carbonated Soft Drinks and Dental Caries in the Primary Dentition. Journal of Dental Research, 85, 262-266. https://doi.org/10.1177/154405910608500311

[19] Bernabé, E., Vehkalahti, M.M., Sheiham, A., Aromaa, A. and Suominen, A.L (2014) Sugar-Sweetened Beverages and Dental Caries in Adults: A 4-Year Prospective Study. Journal of Dentistry, 42, 952-958. https://doi.org/10.1016/j.jdent.2014.04.011

[20] Anderson, C.A., Curzon, M.E., Van Loveren, C., Tatsi, C. and Duggal, M.S. (2009) Sucrose and Dental Caries: A Review of the Evidence. Obesity Reviews, 10, 41-54. 
https://doi.org/10.1111/j.1467-789X.2008.00564.x

[21] Bernabé, E., Delgado-Angulo, E.K., Vehkalahti, M.M., Aromaa, A. and Suominen, A.L. (2014) Daily Smoking and 4-Year Caries Increment in Finnish Adults. Community Dentistry and Oral Epidemiology, 42, 428-434.

https://doi.org/10.1111/cdoe.12101

[22] Farooqi, F.A., Khabeer, A., Moheet, I.A., Khan, S.Q., Farooq, I. and ArRejaie, A.S. (2015) Prevalence of Dental Caries in Primary and Permanent Teeth and Its Relation with Tooth Brushing Habits among Schoolchildren in Eastern Saudi Arabia. Saudi Medical Journal, 36, 737-742. https://doi.org/10.15537/smj.2015.6.10888

[23] Yadav, K. and Prakash, S. (2016) Dental Caries: A Review. Asian Journal of Biomedical and Pharmaceutical Sciences, 6, 1-7.

[24] Inan-Eroglu, E., Ozsin-Ozler, C., Ercim, R.E., Buyuktuncer, Z., Uzamıs-Tekcicek, M. and Bahar Guciz-Doğan, B. (2017) Is Diet Quality Associated with Early Childhood Caries in Preschool Children? A Descriptive Study. The Turkish Journal of Pediatrics, 59, 537-547. https://doi.org/10.24953/turkjped.2017.05.006

[25] Quadri, M.F.A., Shubayr, M.A., Hattan, A.H., Wafi, S.A. and Jafer, A.H. (2018) Oral Hygiene Practices among Saudi Arabian Children and Its Relation to Their Dental Caries Status. International Journal of Dentistry, 2018, Article ID: 3234970. https://doi.org/10.1155/2018/3234970

[26] Shakespeare, W. (1936) The Complete Comedies. Much Ado about Nothing, Act 5 Scene I, Grolier Incorporated Text Copyright, New York, 184-188. 